\title{
Differential Involvement of NMDA, AMPA/Kainate, and Dopamine Receptors in the Nucleus Accumbens Core in the Acquisition and Performance of Pavlovian Approach Behavior
}

\author{
Patricia Di Ciano, Rudolf N. Cardinal, Rosie A. Cowell, Simon J. Little, and Barry J. Everitt \\ Department of Experimental Psychology, University of Cambridge, Cambridge, CB2 3EB, United Kingdom
}

Stimuli paired with primary rewards can acquire emotional valence and the ability to elicit automatic, Pavlovian approach responses that have been shown to be mediated by the nucleus accumbens. The present experiment investigated the effects of infusions of glutamatergic or dopaminergic receptor antagonists into the core of the nucleus accumbens on the acquisition and performance of Pavlovian discriminated approach to an appetitive conditioned stimulus. Rats were trained on an autoshaping task in which a conditioned stimulus (CS+; a lever) was inserted into the operant chamber for $10 \mathrm{sec}$, after which a food pellet was delivered. Presentation of another lever (CS-) was never followed by food. Subjects developed a conditioned response of approaching and contacting the CS+ selectively, although food delivery was not in any way contingent on the animals' response. A triple dissociation in the effects of AP-5, LY293558 [(3SR, 4aRS, 6RS, 8aRS)-6-[2-(iH-tetrazol-5yl)ethyl]-1,2,3,4,4a,5,6,7,8,8a-decahydroiso-quinoline-3- carboxylic acid], and $\alpha$-flupenthixol infused into the nucleus accumbens core on the acquisition and performance of this conditioned response was observed. The AMPA/kainate receptor antagonist LY293558 disrupted discriminated approach performance but not acquisition, as evidenced by increased approaches to the CS-. In contrast, the NMDA receptor antagonist AP-5 impaired only the acquisition, but not performance, of autoshaping whereas the dopamine D1/D2 receptor antagonist $\alpha$-flupenthixol decreased approaches to the CS+ during both acquisition and performance. The data are discussed with reference to dissociable interactions of these receptor types with limbic cortical and dopaminergic afferents to the nucleus accumbens core during the acquisition and expression of Pavlovian conditioned approach.

Key words: glutamate; dopamine; conditioned stimulus; autoshaping; nucleus accumbens core; NMDA; AMPA
Stimuli paired with natural rewards, such as food, or with drugs of abuse can acquire powerful motivational properties, one consequence of which is that they elicit approach responses that serve to bring the subject into contact with goals and, in the case of drug-associated stimuli, can induce craving and relapse to drug use. With an "autoshaping" procedure, it was demonstrated that pigeons approached and pecked a key light presented before the delivery of grain (Brown and Jenkins, 1968). The acquisition of autoshaped key pecking by pigeons (Williams and Williams, 1969) and autoshaped lever pressing by rats (Locurto et al., 1976) was minimally affected when responding prevented delivery of the reinforcer, indicating that autoshaping is subserved by Pavlovian mechanisms (because it is relatively insensitive to the introduction of this instrumental contingency). Autoshaping, therefore, provides the best animal model of the automatic Pavlovian approach behavior elicited by stimuli paired with primary rewards.

Using this procedure, the approach-eliciting properties of Pavlovian cues have been shown to depend on the nucleus accumbens (NAcc) and specific limbic cortical afferents. Thus, selective excitotoxic lesions of the NAcc core (Parkinson et al., 1999) and

\footnotetext{
Received July 13, 2001; revised Sept. 10, 2001; accepted Sept. 14, 2001.

This work was supported by Medical Research Council (MRC) Program Grant G9537855 to B.J.E. and an MRC Cooperative in Brain, Behavior, and Neuropsychiatry. P.D.C. was supported by a Postdoctoral Fellowship from the Natural Sciences and Engineering Research Council of Canada. We thank Dr. H. C. Fibiger and Eli Lilly for generously donating the LY293558.

Correspondence should be addressed to Patricia Di Ciano, Department of Experimental Psychology, University of Cambridge, Downing Street, Cambridge, CB2 3EB, UK. E-mail: pd241@cus.cam.ac.uk.

Copyright (ㄷ) 2001 Society for Neuroscience $0270-6474 / 01 / 219471-07 \$ 15.00 / 0$
}

dopaminergic depletions of the NAcc (Parkinson et al., 2001) abolished the acquisition of autoshaping. Moreover, lesions of the anterior cingulate cortex (ACC) disrupted the acquisition of autoshaping (Bussey et al., 1997), whereas lesions of the basolateral amygdala and dorsal or ventral subiculum were without effect (Parkinson et al., 2000a). In addition, the disruption of discriminated approach after ACC lesions was characterized by an increase in approaches to the cue not associated with reward [conditioned stimulus (CS-)] (Bussey et al., 1997), whereas lesions of the NAcc core and its DA innervation were associated with decreased approach responses to the stimuli paired with reward $(\mathrm{CS}+)$. The finding that lesions that functionally disconnected the ACC and NAcc core produced both decreased approaches to the CS + and increased approaches to the CS- (Parkinson et al., $2000 \mathrm{~b}$ ) underscores the critical role of interactions between the NAcc and its limbic cortical afferents in this form of appetitive emotional learning.

Limbic afferents to the NAcc have been shown to interact with dopamine (DA) in the NAcc in a manner that is glutamate dependent (Wu and Brudzynski, 1995; Blaha et al., 1997; Floresco et al., 1998; Taepavarapruk et al., 2000). In this regard, infusion of the NMDA receptor antagonist D-(-)-2-aminophosphonopentanoic acid (AP-5) into the NAcc core has been shown to impair the acquisition, but not performance, of an instrumental response (Kelley et al., 1997). In contrast, AMPA/ kainate (KA) receptors have been shown to have a selective role in the control over behavior by Pavlovian conditioned stimuli (Di Ciano and Everitt, 2001; Roullet et al., 2001). Important questions still remain, however, as to the differential involvement of 
glutamatergic and dopaminergic receptors in the acquisition and expression of a Pavlovian appetitive conditioned response. The present experiment, therefore, investigated the effects of antagonism of NMDA, AMPA/KA, and DA receptors in the NAcc core on the acquisition and performance of discriminated Pavlovian approach to an appetitive CS in an autoshaping paradigm.

\section{MATERIALS AND METHODS}

\section{Animals}

Sixty-two male Lister hooded rats (Charles River, Kent, UK) weighing 250-300 gm at the time of surgery were individually housed under a reversed $12 \mathrm{hr}$ light/dark cycle (lights on at 8:00 P.M.). During training and testing, rats were maintained on a restricted diet of $12 \mathrm{gm}$ of Purina lab chow per day. Water was available ad libitum, and food was given $<2$ $\mathrm{hr}$ after daily testing. Experiments were performed between 9:00 A.M. and 8:00 P.M., 6 or $7 \mathrm{~d} /$ week, and experiments were conducted in accordance with the United Kingdom 1986 Animals (Scientific Procedures) Act (Project License PPL 80/1324).

\section{Apparatus}

Rats were tested in operant chambers $(29.5 \times 32.5 \times 23.5 \mathrm{~cm}$; Med Associates Inc., E. Fairfield, VT). Three sides were constructed from Perspex, and the fourth was made of stainless steel, on which two 4-cm-wide retractable levers were situated. The two levers were $12 \mathrm{~cm}$ apart and $8 \mathrm{~cm}$ from the grid floor. Above each lever was a $2.5 \mathrm{~W}$ white cue light, and a $2.5 \mathrm{~W}$ white house light was located on the opposite wall. Food was delivered through a magazine that was equidistant from the two levers and $3 \mathrm{~cm}$ above the floor. The floor of the chamber was lined with absorbent paper and covered with a metal grid. The testing chamber was placed within a sound- and light-attenuating box, equipped with a ventilation fan that also screened external noise. The operant chamber was interfaced to software running on an Acorn Archimedes microcomputer (Acorn Computers Ltd., Cambridge, UK), programmed in the BASIC control language Arachnid.

\section{Surgery}

Rats were anesthetized with ketamine hydrochloride $(100 \mathrm{mg} / \mathrm{kg}$, i.p.; Ketaset; VetDrug, Dunnington, UK) and xylazine ( $9 \mathrm{mg} / \mathrm{kg}$, i.p.; Rompun; VetDrug) and supplemented with ketamine as needed $(\sim 20$ $\mathrm{mg}$ ). Guide cannulas consisted of 24 ga thin-walled stainless steel tubing (Coopers Needle Works, Birmingham, UK) and were lowered to $2.5 \mathrm{~mm}$ above the target site [NAcc core: $+1.2 \mathrm{~mm}$ anteroposterior; $\pm 1.8 \mathrm{~mm}$ mediolateral; $-4.7 \mathrm{~mm}$ dorsoventral from skull; incisor bar, $-3.3 \mathrm{~mm}$ (Paxinos and Watson, 1986)]. Cannulas were secured with stainless steel screws and dental acrylic; 29 ga wire stylets (Coopers Needle Works) were inserted into the length of the guide cannulas to maintain patency.

\section{Microinfusions}

Intracerebral microinfusions were made through a 28 ga cannula (Semat Technical, St. Albans, UK), which was lowered to the site of injection in the core of the NAcc $(-7.2 \mathrm{~mm}$ dorsoventral relative to skull), $2.5 \mathrm{~mm}$ below the guide cannula. All infusions were $0.5 \mu \mathrm{l} / \mathrm{side}$, over $90 \mathrm{sec}$, delivered using a syringe pump (model 975A; Harvard Apparatus) and followed by a $90 \mathrm{sec}$ diffusion time. After all infusions, stylets were replaced, and the animal was left in a holding box for 5 min before testing. All rats received one infusion of phosphate-buffered vehicle before testing, to habituate the animal to the injection procedure $[0.1 \mathrm{M}$ phosphate-buffered water (PB); composition of $0.07 \mathrm{M} \mathrm{Na}_{2} \mathrm{HPO}_{4}$ and $0.028 \mathrm{M} \mathrm{NaH}_{2} \mathrm{PO}_{4}$, giving an approximate $\mathrm{pH}$ of 7.3]. The habituation session and all drug infusions were separated by at least $1 \mathrm{~d}$ of stable performance without treatment.

\section{Drugs}

The competitive NMDA receptor antagonist AP-5 was obtained from Sigma (Poole, UK) and was dissolved in sterile PB. The selective AMPA/KA receptor antagonist $(3 S R, 4 \mathrm{a} R S, 6 R S, 8 \mathrm{a} R S)-6-[2-(\mathrm{iH}-$ tetrazol-5-yl)ethyl]-1,2,3,4,4a,5,6,7,8,8a-decahydroiso-quinoline-3carboxylic acid (LY293558) is the (-)-isomer of the racemic compound $( \pm) L Y 215490$, is 10 -fold selective for AMPA over NMDA receptors (Schoepp et al., 1995), and was a gift from Eli Lilly \& Co. (Indianapolis, IN). LY293558 was dissolved in sterile PB, divided into aliquots, and frozen at $-5^{\circ} \mathrm{C}$ until use. The dopamine receptor antagonist cis-(Z)- flupenthixol was obtained from Sigma and was dissolved in distilled water.

\section{Procedure}

During daily training, rats were placed in the operant chambers immediately before the start of each session when the house light was illuminated. Sessions lasted on average $1 \mathrm{hr}$ and consisted of 50 trials. During 25 of these trials, the CS+ lever was inserted into the operant chamber for $10 \mathrm{sec}$, followed immediately by delivery of one $45 \mathrm{mg}$ food pellet (Rodent Diet Formula P; Noyes, Lancaster, NH) after retraction of the lever. The remaining 25 trials consisted of insertion of the CS- lever into the chamber for $10 \mathrm{sec}$, but food was not delivered. Contacts with each lever were recorded but had no programmed consequences. The intertrial interval ranged between 45 and $75 \mathrm{sec}$, and the order of presentation of the CS+ and CS - was random. The CS+ and CS- levers were counterbalanced left-right across rats.

Acquisition experiment. Naïve rats were implanted with intracerebral cannulas (see above). Five to $7 \mathrm{~d}$ after surgery, rats were randomly assigned to one of four treatment groups: AP-5, LY293558, $\alpha$-flupenthixol, or vehicle control. The lowest effective dose from the dose-response study was used, such that each rat received $0.02 \mu \mathrm{g}(0.067$ nmol equivalent) of LY293558, $10 \mu \mathrm{g}$ (20 nmol equivalent) of $\alpha$-flupenthixol, or an equal volume of PB, before each of the first $6 \mathrm{~d}$ of acquisition of autoshaping. For the NMDA receptor antagonist group, rats were infused with $1 \mu \mathrm{g}$ ( $5 \mathrm{nmol}$ equivalent) of AP-5 because this dose has been shown previously to be effective in blocking the acquisition of an instrumental response for food reward (Kelley et al., 1997). All other parameters were the same as described above.

Performance experiment. Unoperated naïve rats were trained until stable approach responses to the CS + and CS - stimuli was observed, after $\sim 14 \mathrm{~d}$ of training, and were then implanted with guide cannulas bilaterally in the NAcc core (see above). After 5-7 d of recovery from surgery, rats were given additional training sessions until their performance returned to preoperative levels $(\sim 3 \mathrm{~d})$. Rats were randomly assigned to receive intracore infusions of one of LY293558, AP-5, or $\alpha$-flupenthixol intracerebrally. All drugs were given in four doses counterbalanced according to a Latin square design (Keppel, 1991). The doses administered to the three groups were as follows: AP-5, 0.2, 1, and $2 \mu \mathrm{g}$ of $\mathrm{PB}$ (equivalent to 1,5 , and $10 \mathrm{nmol}$, respectively); LY293558, $0.002,0.02$, and $0.04 \mu \mathrm{g}$ of $\mathrm{PB}$ (equivalent to $0.0067,0.067$, and $0.13 \mathrm{nmol}$, respectively); and $\alpha$-flupenthixol, 1,10 , and $25 \mu \mathrm{g}$ of $\mathrm{ddH}_{2} \mathrm{O}$ (equivalent to 2,20 , and $50 \mathrm{nmol}$, respectively).

\section{Histological assessment of cannula placements}

At the end of testing, rats were killed with an overdose of sodium pentobarbitone (1.5 ml, i.p.; Euthatal; Rhône-Mérieux, Hertfordshire, UK) and perfused transcardially with PBS, followed by $4 \%$ paraformaldehyde in 0.01 M PBS. Brains were then removed and post-fixed in $4 \%$ paraformaldehyde at least $24 \mathrm{hr}$ before being transferred to a $20 \%$ sucrose solution in $0.01 \mathrm{M}$ PBS for $24 \mathrm{hr}$ before being sectioned at $60 \mu \mathrm{m}$ using a freezing microtome. Every third section was mounted and stained with cresyl violet, and cannula placements were verified under a light microscope.

\section{Statistical analyses}

Data were recorded as number of lever presses during each CS presentation and were presented as the probability of approach to each CS, calculated by dividing the number of trials in which each lever was pressed at least once by the number of presentations of that CS (i.e., 25). Data are presented as mean \pm SEM.

Acquisition experiment. The effect of administration of AP-5, LY293558, or $\alpha$-flupenthixol into the core during acquisition of autoshaping was analyzed with a repeated-measures day (six levels) $\times$ stimulus (two levers) $\times$ group (four levels) ANOVA.

Performance experiment. To confirm that the three groups of rats had comparable rates of acquisition and baseline performance before treatments, the probability of approaching each stimulus during the first $10 \mathrm{~d}$ of acquisition was analyzed with a repeated-measures group (three levels $) \times$ stimulus (two levels $) \times$ day $(10$ levels $)$ ANOVA. To investigate the effects of drug administration on performance of discriminated approach, a dose-response analysis was conducted with a repeatedmeasures group (three levels) $\times$ dose (four levels) $\times$ stimulus (two levels) analysis.

For all analyses, significant interactions were further analyzed with simple main effects and planned comparisons. The criterion for signifi- 
A

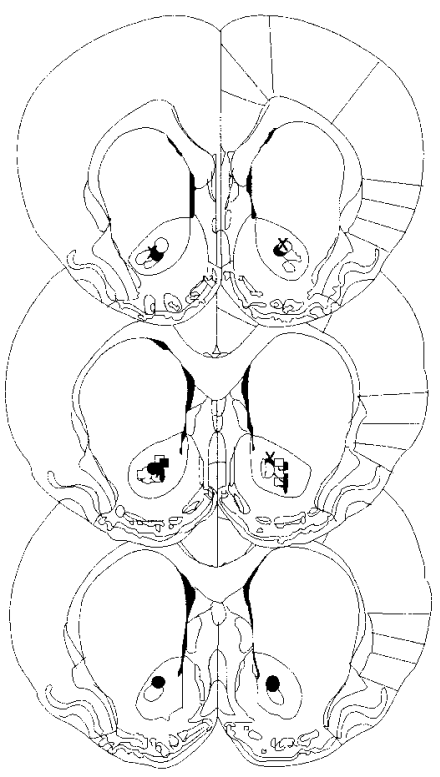

B

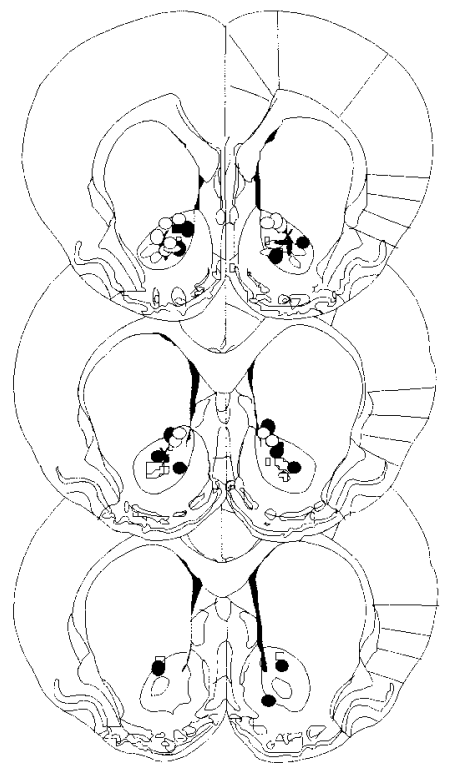

Figure 1. Location of the tips of injection cannulas within the NAcc core for the performance $(A)$ and acquisition $(B)$ experiments. Symbols represent the bilateral placement of the injections for individual animals. Schematics of coronal sections are taken from Paxinos and Watson (1986).

cance was set at $p \leq 0.05$, and the Huynh-Feldt correction for nonsphericity was used for all within-subjects analyses (denoted as $p_{\mathrm{HF}}$ ).

\section{RESULTS}

\section{Cannula placements}

Figure 1 illustrates the location of the tips of injection cannulas within the NAcc core for the performance $(A)$ and acquisition $(B)$ experiments. Four rats were excluded from the analyses of the acquisition experiment because the tips of their cannulas were not in the NAcc core. One rat from each of the LY293558 and flupenthixol groups was excluded because of illness. Final group sizes were $n=8$.

$\alpha$-Flupenthixol and AP-5, but not LY293558, infused into the nucleus accumbens core disrupted acquisition of autoshaping

Acquisition

Infusion of AP-5, LY293558, $\alpha$-flupenthixol, or vehicle into the NAcc core was associated with differential effects on the acquisition of Pavlovian discriminated approach to the two stimuli. After infusions of LY293558 into the NAcc core, rats acquired the discrimination by the fourth day of training no differently from controls who received PB inf usions into the NAcc core (Fig. 2). In contrast, after infusion of AP-5 or $\alpha$-flupenthixol, rats failed to acquire the discrimination between the two stimuli. A dissociation in the effects of these treatments on the acquisition of autoshaping was confirmed by a significant three-way group $\times$ day $\times$ stimulus interaction $\left(n=8 ; F_{(5,140)}=2.95, p_{\mathrm{HF}}=0.003\right)$ (Fig. 2). Additional analysis of the interaction revealed stimulus $\times$ day interactions for both the vehicle (Fig. 2A) and LY293558 groups $\left(n=8\right.$; for vehicle, $F_{(5,35)}=8.31, p_{\mathrm{HF}}=0.000$; for LY293558, $\left.F_{(5,35)}=6.28, p_{\mathrm{HF}}=0.000\right)$ (Fig. $2 B$ ), confirming that these two groups of rats acquired the discrimination. Additional analysis of these interactions with planned comparisons

revealed that, for both of these groups, the probability of approach to the levers was different on days 5 and 6 only (for vehicle: day $5, F_{(1,7)}=8.66, p_{\mathrm{HF}}=0.02$; day $6, F_{(1,7)}=14.88, p_{\mathrm{HF}}=0.006$; for LY293558: day $5, F_{(1,7)}=9.11, p_{\mathrm{HF}}=0.019$; day $6, F_{(1,7)}=$ $\left.10.04, p_{\mathrm{HF}}=0.016\right)$.

\section{$\alpha$-Flupenthixol and LY293558, but not AP-5, infused into the nucleus accumbens core disrupted performance of conditioned approach}

\section{Acquisition}

Figure 3 illustrates the preoperative acquisition of discriminated approach to a stimulus paired with food reward. The three groups represent the treatment conditions that the animals received in subsequent performance tests and demonstrated that the three groups were similar before treatments. All three groups progressively learned to discriminate between the two stimuli by day 4 . Asymptotic performance was reached by day 10, with a probability of approach of $\sim 0.8$ and $\sim 0.15$ to the CS + and CS - stimuli, respectively. A three-way stimulus $\times$ group $\times$ day ANOVA revealed a significant stimulus $\times$ day interaction, confirming that all three groups of rats learned the discrimination by day $10(n=$ $\left.8 ; F_{(9,189)}=24.48, p_{\mathrm{HF}}<0.001\right)$.

\section{Performance}

All rats returned to preoperative levels of responding within $2 \mathrm{~d}$ of postoperative training. A triple dissociation in the effects of $\alpha$-flupenthixol, AP-5, and LY293558 on discriminated approach to the stimuli was observed. Thus, LY293558 infusions resulted in increased approaches to the CS- only, whereas flupenthixol decreased approaches to the CS+ only, and AP-5 was without effect on approaches to either stimulus (Fig. 4). This dissociation was confirmed by a significant stimulus $\times$ dose $\times$ group interaction $\left(n=8 ; F_{(6,63)}=3.931, p_{\mathrm{HF}}=0.004\right)$. Additional analysis of this interaction confirmed that infusion of LY293558 into the core was associated with differential effects on approach to the two stimuli, as revealed by a significant stimulus $\times$ dose interaction $\left(F_{(3,21)}=9.55, p_{\mathrm{HF}}=0.008\right)$ (Fig. $\left.4 A\right)$. Additional analysis of this interaction revealed that LY293558 produced significant increases in approach to the $\mathrm{CS}-$ stimulus only $\left(n=8 ; F_{(3,21)}=\right.$ 4.13, $\left.p_{\mathrm{HF}}=0.019\right)($ Fig. $4 A)$. A significant stimulus $\times$ dose interaction was also revealed after treatment with $\alpha$-flupenthixol $\left(F_{(3,21)}=10.13, p_{\mathrm{HF}}=0.002\right)($ Fig. $4 B)$, whereas $\alpha$-flupenthixol produced significant decreases in approaches to the $\mathrm{CS}+(n=8$; $F_{(3,21)}=8.76, p_{\mathrm{HF}}=0.003$ ) (Fig. $4 B$ ) and small, albeit significant, increases in approach to the CS $-\left(n=8 ; F_{(3,21)}=3.98, p_{\mathrm{HF}}=\right.$ 0.025). No significant effects were revealed for AP-5 (Fig. 4C).

\section{DISCUSSION}

The present study was designed to investigate the effects of antagonism of AMPA/KA, NMDA, or DA receptors in the NAcc core on the acquisition and performance of discriminated Pavlovian approach to an appetitive CS using an autoshaping procedure (Brown and Jenkins, 1968). Because this behavior is minimally sensitive to changes in the instrumental contingency for the reward, it is believed to depend on a Pavlovian mechanism (Williams and Williams, 1969) and thus provides the best animal model of the automatic, compulsive approach to conditioned stimuli paired with rewards. A triple dissociation in the effects of the three receptor antagonists on the acquisition and performance of discriminated approach was observed. Inf usion of the AMPA/KA receptor antagonist LY293558 into the core impaired only performance of the autoshaped approach response by 

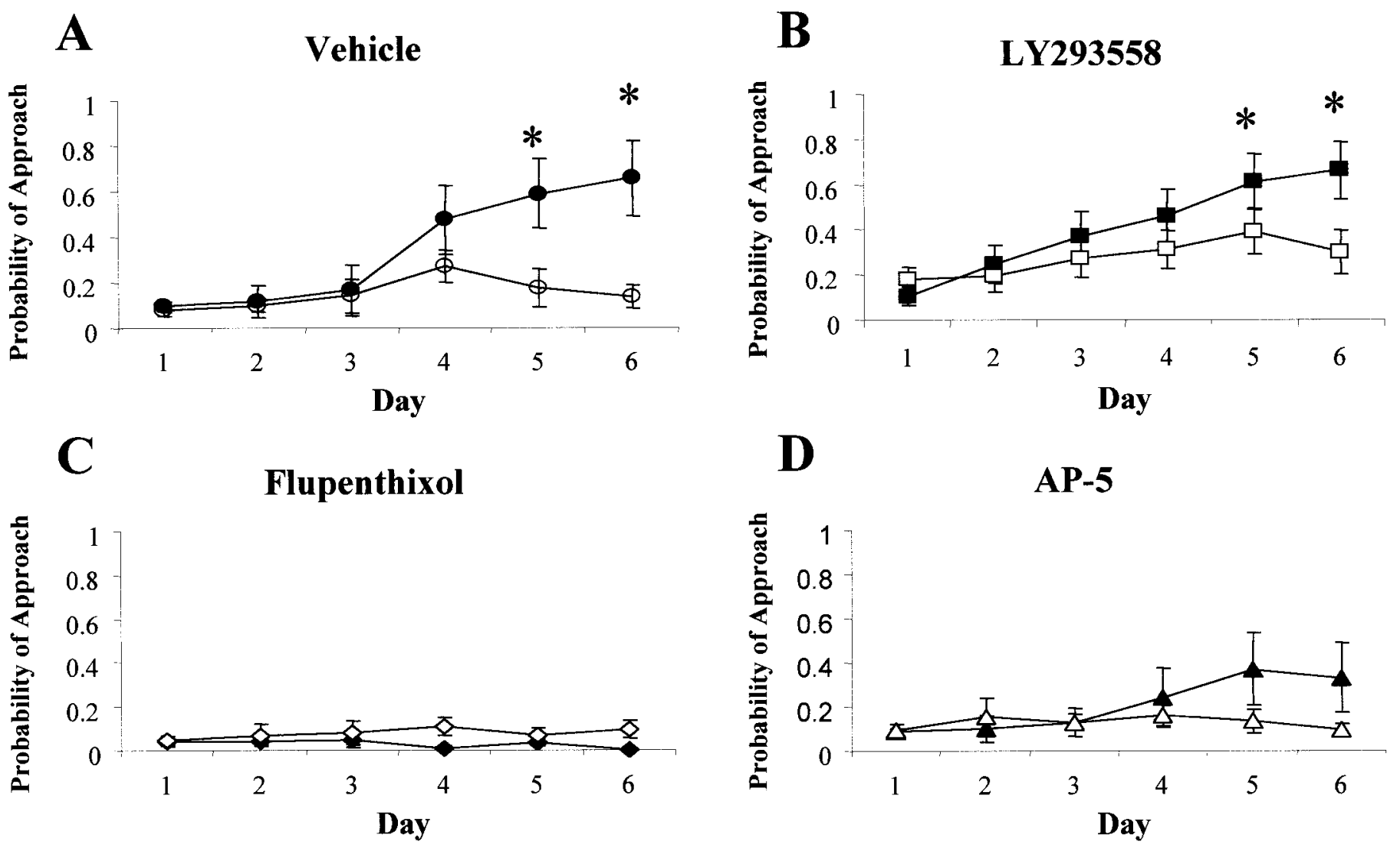

Figure 2. Effects of infusion of vehicle $(A)$, the AMPA/KA antagonist LY293558 $(0.02 \mu \mathrm{g})(B)$, the DA antagonist $\alpha$-flupenthixol $(10 \mu \mathrm{g})(C)$, and the NMDA antagonist AP-5 $(1 \mu \mathrm{g})(D)$ on the acquisition of autoshaping. Day $\times$ stimulus interaction: for vehicle, $p<0.001$; for LY293558, $p<0.001$. *indicates days at which approach to the two levers was significantly different; $p<0.05$ (planned comparisons).

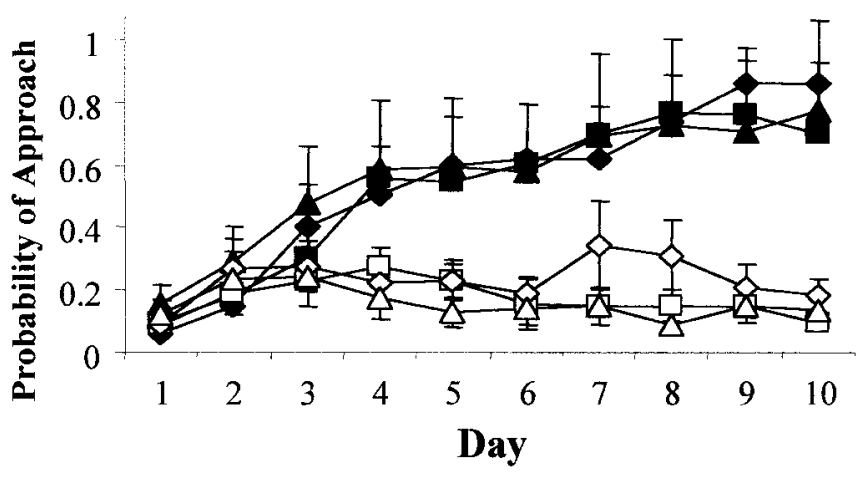

Figure 3. Acquisition of autoshaping. Filled and open symbols represent the probability of approach to the CS + and CS - stimuli, respectively. Squares, triangles, and diamonds represent the LY293558, AP-5, and $\alpha$-flupenthixol treatment groups, respectively, that the rats were assigned to after acquisition. Day $\times$ stimulus interaction, $p<0.001$.

increasing approaches to the $\mathrm{CS}-$; it had no effect on acquisition. In contrast, the NMDA receptor antagonist AP-5 impaired only the acquisition of autoshaping, whereas the mixed, D1/D2 DA receptor antagonist $\alpha$-flupenthixol decreased approaches to the $\mathrm{CS}+$ during both acquisition and performance of the conditioned response.

\section{DA and NMDA receptor antagonists infused into the NAcc blocked the acquisition of autoshaping}

Consistent with much evidence implicating both NMDA and DA receptors in learning (Berke and Hyman, 2000), both AP-5 and $\alpha$-flupenthixol infused into the NAcc core disrupted the acquisition of autoshaping. NMDA receptors in particular have been shown to be involved in processes believed to underlie learning (Davis et al., 1992; Shimizu et al., 2000) and have been shown to be important in the acquisition of a variety of behaviors, including spatial learning (Bannerman et al., 1995; Smith-Roe et al., 1999). Moreover, antagonism of NMDA receptors blocked the establishment of a Pavlovian conditioned eye-blink response in rabbits (Chen and Steinmetz, 2000), whereas the firing rate of A10 neurons projecting to the NAcc was increased by a CS only during the early stages of learning its association with reward (Ljungberg et al., 1992). Moreover, systemic administration of either NMDA or DA receptor antagonists blocked the acquisition, but not expression, of conditioned motor activity (Beninger and Hahn, 1983; Cervo and Samanin, 1996) and a conditioned place preference (Cervo and Samanin, 1995).

Direct manipulations of DA and NMDA receptors in the NAcc core have also been shown to disrupt the acquisition of conditioned responding. Thus, 6-OHDA lesions blocked the learning of a discriminated approach response to a CS predictive of food in an autoshaping procedure (Parkinson et al., 2001), whereas infusion of AP-5 into the NAcc core at the same doses used in the present study blocked the acquisition of an instrumental response for food (Kelley et al., 1997; Baldwin et al., 2000). However, intracore infusion of the NMDA receptor antagonist MK-801 [(+)-5-methyl-10,11-dihydro-5H-dibenzo [a,d] cyclohepten-5,10imine maleate] blocked not only the acquisition but also the performance of a multiple chain schedule response for food in 


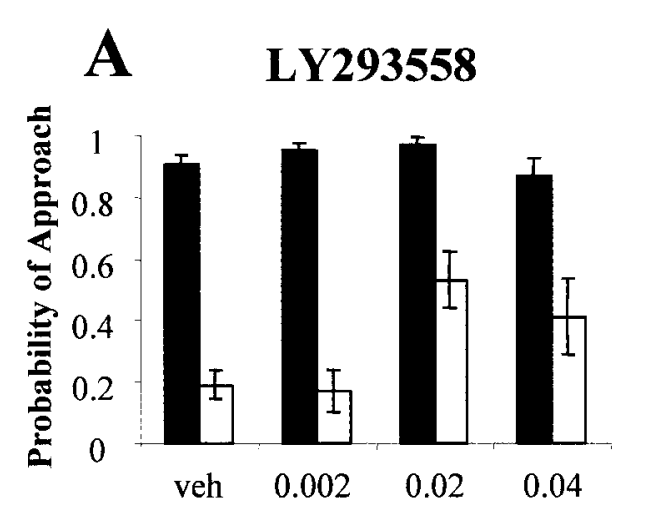

B Flupenthixol

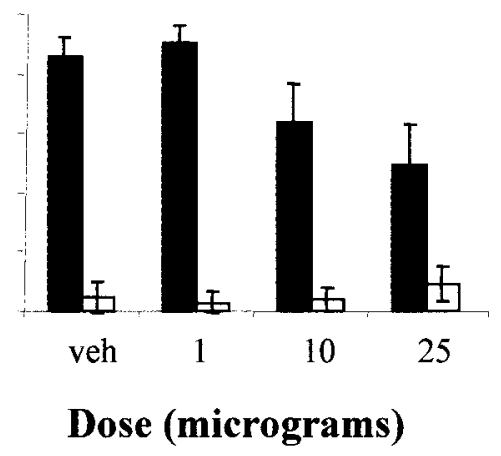

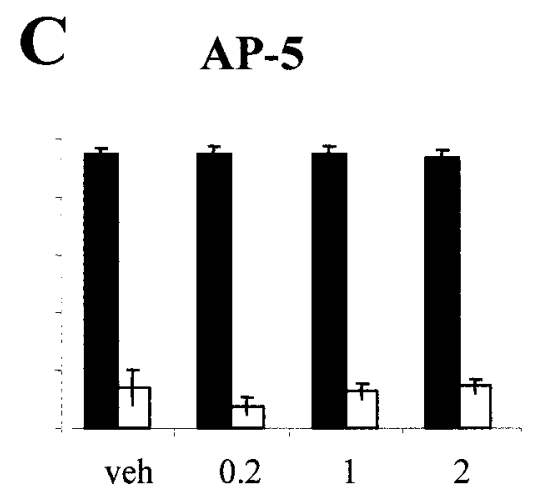

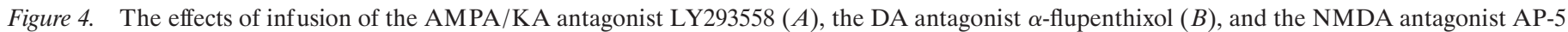

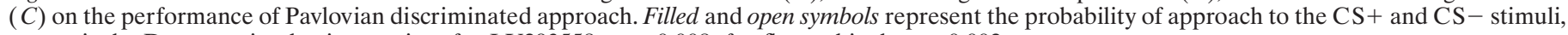
respectively. Dose $\times$ stimulus interaction: for LY293558, $p=0.008$; for flupenthixol, $p=0.002$.

rats (Cory-Slechta et al., 1999), suggesting that NMDA receptors may also participate under certain conditions in ongoing complex behaviors.

NMDA and DA receptors have also been shown to interact in the acquisition of goal-directed behaviors. When infused together into the NAcc core, AP-5 and the D1 receptor antagonist SCH-23390 $[R(+)$-7-chloro-8-hydroxy-3-methyl-1-phenyl-2,3,4,5tetrahydro-1H-3-benzazepine hydrochloride] blocked the acquisition of an instrumental response for food at low doses of each of these drugs that were ineffective on their own (Smith-Roe and Kelley, 2000), suggesting that these two receptors may interact critically during learning (Berke and Hyman, 2000). The functional importance of interactions between DA and glutamate receptors has also been established in studies of locomotor activity. For example, NMDA increased NAcc DA efflux, which was shown to be associated with increased motor activity (Svensson et al., 1994), whereas locomotor activity induced by intra-NAcc infusions of NMDA was attenuated by DA receptor antagonists, suggesting that DA may mediate glutamate-induced increases in motor activity (Wu et al., 1993). The converse is also true in that AP-5 inhibited cocaine-induced increases in DA when it was administered through a dialysis probe, with no effects on basal levels of DA (Pap and Bradberry, 1995).

\section{$\alpha$-Flupenthixol and LY293558 disrupt discriminated Pavlovian approach to a CS}

Infusion of the AMPA/KA receptor antagonist LY293558 into the core disrupted the performance of an already acquired discriminated approach by increasing the probability of approach to the CS - only. This is consistent with previous findings that AMPA/KA receptors have a greater contribution to the performance, rather than the acquisition, of learned behaviors (Cervo and Samanin, 1995; Kelley et al., 1997; Roullet et al., 2001). For example, infusion of LY293558 into the core decreased responding for cocaine under a second-order schedule of reinforcement, whereas lever presses on an inactive lever increased (Di Ciano and Everitt, 2001), implicating AMPA/KA receptors in the NAcc core in the discriminated response to stimuli predictive of reward. In contrast, intracore AP-5 was without effect on the performance of this response, as in the present experiment. It is noteworthy that lesions of the ACC also impaired autoshaping by increasing approaches to the CS- (Bussey et al., 1997). Given that the ACC projects to the core (Groenewegen et al., 1987; Groenewegen et al., 1996, 1999) and that its disconnection from the core also impaired the acquisition of autoshaping (Parkinson et al., 2000b), the impaired discrimination after LY293558 may depend on disruption of ACC-dependent processes within the NAcc.

Inf usion of the DA receptor antagonist into the NAcc core also blocked discriminated approach to the CS+. Together with similar findings after 6-OHDA lesions of the NAcc (Parkinson et al., 2001), this suggests an important role for DA in the NAcc in both the acquisition and performance of responses under the control of a Pavlovian CS. Because DA depletions from the NAcc do not affect consumption of food (Koob et al., 1978; Parkinson et al., 2001) or the palatability or hedonics of the primary reward (Berridge et al., 1989; Pecina et al., 1997), the effect seems specific to conditioned responses to incentive stimuli. Thus, DA receptor antagonism produced a selective attenuation of approach to the appetitive $\mathrm{CS}+$, suggesting that it may influence the vigor of responding directed toward Pavlovian stimuli (Cador et al., 1989; Parkinson et al., 2000b), and this may also underlie the effects seen in acquisition. Indeed, inf usion of DA receptor agonists into the NAcc increased the ability of a Pavlovian stimulus to enhance instrumental responding without influence on the hedonic value of the reward (Wyvell and Berridge, 2000), whereas infusion of DA receptor agonists into the NAcc increased responding for a conditioned stimulus (Wolterink et al., 1993). Together, these findings suggest an important role for DA in the NAcc in approach elicited by Pavlovian stimuli, which may be critical in both the establishment and expression of conditioned approach and preparatory behaviors (Blackburn et al., 1987, 1989; Pfaus et al., 1990; Fiorino et al., 1997).

\section{Conclusions}

Consistent with an originally suggested role for the NAcc as a limbic-motor interface (Mogenson et al., 1980), recent neuroanatomical and neurochemical evidence supports the existence of a limbic cortical-ventral striatal neural circuit subserving Pavlovian approach behavior that converges on the NAcc core. For example, bilateral lesions of the core (Parkinson et al., 1999), central amygdala (Parkinson et al., 2000a), or ACC (Bussey et al., 1997) abolished the acquisition of autoshaping, whereas the core and ACC have been shown to interact critically in the acquisition of autoshaping (Parkinson et al., 2000b). In the present study, we supported and extended these findings by demonstrating that antagonism of $\mathrm{DA}, \mathrm{NMDA}$, or $\mathrm{AMPA} / \mathrm{KA}$ receptors in the 
NAcc core differentially disrupted the acquisition and performance of discriminated approach, which indicates that these receptor types have differential control over the learning and performance of this Pavlovian conditioned response. In support of a role for DA in anticipatory behaviors directed selectively at a stimulus predictive of reward, antagonism of DA receptors disrupted both the acquisition and performance of approach to the $\mathrm{CS}+$. Furthermore, AMPA/KA receptor antagonism disrupted discrimination of the two stimuli during performance only, and we suggest that this receptor may mediate the impact of ACC processes on approach behavior through its glutamatergic projections to the NAcc core. In support of a wealth of evidence implicating NMDA receptors in learning, AP-5 infused into the NAcc core impaired the acquisition, but not performance, of this approach response. Together, these results suggest that the NAcc core mediates the acquisition and expression of Pavlovian conditioned responses toward drug-paired stimuli by acting as an interface between limbic-cortical processes and downstream response mechanisms.

\section{REFERENCES}

Baldwin AE, Holahan MR, Sadeghian K, Kelley AE (2000) $N$-methylD-aspartate receptor-dependent plasticity within a distributed corticostriatal network mediates appetitive instrumental learning. Behav Neurosci 114:84-98.

Bannerman DM, Good MA, Butcher SP, Ramsay M, Morris RG (1995) Distinct components of spatial learning revealed by prior training and NMDA receptor blockade. Nature 378:182-186.

Beninger RJ, Hahn BL (1983) Pimozide blocks the establishment but not the expression of amphetamine-produced environment-specific conditioning. Science 220:1304-1306.

Berke JD, Hyman SE (2000) Addiction, dopamine, and the molecular mechanisms of memory. Neuron 25:515-532.

Berridge KC, Venier IL, Robinson TE (1989) Taste reactivity analysis of 6-hydroxydopamine-induced aphagia: implications for arousal and anhedonia hypotheses of dopamine function. Behav Neurosci 103:36-45.

Blackburn JR, Phillips AG, Fibiger HC (1987) Dopamine and preparatory behavior. I. Effects of pimozide. Behav Neurosci 101:352-360.

Blackburn JR, Phillips AG, Jakubovic A, Fibiger HC (1989) Dopamine and preparatory behavior. II. A neurochemical analysis. Behav Neurosci 103:15-23.

Blaha CD, Yang CR, Floresco SB, Barr AM, Phillips AG (1997) Stimulation of the ventral subiculum of the hippocampus evokes glutamate receptor-mediated changes in dopamine efflux in the rat nucleus accumbens. Eur J Neurosci 9:902-911.

Brown PL, Jenkins HM (1968) Auto-shaping of the pigeon's key-peck. J Exp Anal Behav 11:1-8.

Bussey TJ, Everitt BJ, Robbins TW (1997) Dissociable effects of cingulate and medial frontal cortex lesions on stimulus-reward learning using a novel Pavlovian autoshaping procedure for the rat: implications for the neurobiology of emotion. Behav Neurosci 111:908-919.

Cador M, Robbins TW, Everitt BJ (1989) Involvement of the amygdala in stimulus-reward associations: interaction with the ventral striatum. Neuroscience 30:77-86.

Cervo L, Samanin R (1995) Effects of dopaminergic and glutamatergic receptor antagonists on the acquisition and expression of cocaine conditioning place preference. Brain Res 673:242-250.

Cervo L, Samanin R (1996) Effects of dopaminergic and glutamatergic receptor antagonists on the establishment and expression of conditioned locomotion to cocaine in rats. Brain Res 731:31-38.

Chen G, Steinmetz JE (2000) Intra-cerebellar infusion of NMDA receptor antagonist AP5 disrupts classical eyeblink conditioning in rabbits. Brain Res 887:144-156.

Cory-Slechta DA, O'Mara DJ, Brockel BJ (1999) Learning versus performance impairments following regional administration of MK-801 into nucleus accumbens and dorsomedial striatum. Behav Brain Res 102:181-194.

Davis S, Butcher SP, Morris RG (1992) The NMDA receptor antagonist D-2-amino-5-phosphonopentanoate (D-AP5) impairs spatial learning and LTP in vivo at intracerebral concentrations comparable to those that block LTP in vitro. J Neurosci 12:21-34.

Di Ciano P, Everitt BJ (2001) Dissociable effect of antagonism of NMDA and AMPA/KA receptors in the nucleus accumbens core and shell on cocaine-seeking behaviour. Neuropsychopharmacology 25:341-360.
Fiorino D, Coury A, Phillips AG (1997) Dynamic changes in nucleus accumbens dopamine efflux during the Coolidge effect in male rats. J Neurosci 17:4849-4855.

Floresco SB, Yang CR, Phillips AG, Blaha CD (1998) Basolateral amygdala stimulation evokes glutamate receptor-dependent dopamine efflux in the nucleus accumbens of the anaesthetized rat. Eur J Neurosci 10:1241-1251.

Groenewegen HJ, Vermeulen-Van der Zee E, te Kortschot A, Witter MP (1987) Organization of the projections from the subiculum to the ventral striatum in the rat. A study using anterograde transport of Phaseolus vulgaris leucoagglutinin. Neuroscience 23:103-120.

Groenewegen HJ, Wright CI, Beijer AVJ (1996) The nucleus accumbens: gateway for limbic structures to reach the motor system. In: Progress in brain research, Ed 12547 (Holstege G, Bandler R, Saper CB, eds), pp 485-511. Amsterdam: Elsevier Science.

Groenewegen HJ, Wright CI, Beijer AV, Voorn P (1999) Convergence and segregation of ventral striatal inputs and outputs. Ann NY Acad Sci 877:49-63.

Kelley AE, Smith-Roe SL, Holahan MR (1997) Response-reinforcement learning is dependent on $N$-methyl-D-aspartate receptor activation in the nucleus accumbens core. Proc Natl Acad Sci USA 94:12174-12179.

Keppel G (1991) Design and analysis: a researcher's handbook (Finnemore S, Riker, E, Nassauer C, eds). Upper Saddle River, NJ: Prentice Hall.

Koob GF, Riley SJ, Smith SC, Robbins TW (1978) Effects of 6-hydroxydopamine lesions of the nucleus accumbens septi and olfactory tubercle on feeding, locomotor activity, and amphetamine anorexia in the rat. J Comp Physiol Psychol 92:917-927.

Ljungberg, Apicella P, Schultz W (1992) Responses of monkey dopamine neurons during learning of behavioral reactions. J Neurophysiol 67:145-163.

Locurto C, Terrace HS, Gibbon J (1976) Autoshaping, random control, and omission training in the rat. J Exp Anal Behav 26:451-462.

Mogenson GJ, Jones DL, Yim CY (1980) From motivation to action: functional interface between the limbic system and motor system. Prog Neurobiol 14:69-97.

Pap A, Bradberry CW (1995) Excitatory amino acid antagonists attenuate the effects of cocaine on extracellular dopamine in the nucleus accumbens. J Pharmacol Exp Ther 274:127-133.

Parkinson JA, Olmstead MC, Burns LH, Robbins TW, Everitt BJ (1999) Dissociation in effects of lesions of the nucleus accumbens core and shell on appetitive Pavlovian approach behavior and the potentiation of conditioned reinforcement and locomotor activity by D-amphetamine. J Neurosci 19:2401-2411.

Parkinson JA, Robbins TW, Everitt BJ (2000a) Dissociable roles of the central and basolateral amygdala in appetitive emotional learning. Eur J Neurosci 12:405-413.

Parkinson JA, Willoughby PJ, Robbins TW, Everitt BJ (2000b) Disconnection of the anterior cingulate cortex and nucleus accumbens core impairs Pavlovian approach behavior: further evidence for limbic cortical-ventral striatopallidal systems. Behav Neurosci 114:42-63.

Parkinson J, Dalley J, Cardinal R, Bamford A, Fehnert B, Lachenal G, Rudarakanchana N, Halkerston K, Robbins T, Everitt B (2001) Nucleus accumbens dopamine depletion impairs both acquisition and performance of appetitive Pavlovian approach behaviour: implications for mesoaccumbens dopamine function. Behav Brain Res, in press.

Paxinos G, Watson C (1986) The rat brain in stereotaxic coordinates. Sydney: Academic.

Pecina S, Berridge KC, Parker LA (1997) Pimozide does not shift palatibility: separation of anhedonia from sensorimotor suppression by taste reactivity. Pharmacol Biochem Behav 58:801-811.

Pfaus JG, Damsma G, Nomikos GG, Wenkstern DG, Blaha CD, Phillips AG, Fibiger HC (1990) Sexual behavior enhances central dopamine transmission in the male rat. Brain Res 530:345-348.

Roullet P, Sargolini F, Oliverio A, Mele A (2001) NMDA and AMPA antagonist infusions into the ventral striatum impair different steps of spatial information processing in a nonassociative task in mice. J Neurosci 21:2143-2149.

Schoepp DD, Lodge D, Bleakman D, Leander JD, Tizzano JP, Wright RA, Palmer AJ, Salhoff CR, Ornstein PL (1995) In vitro and in vivo antagonism of AMPA receptor activation by $(3 S, 4 \mathrm{a} R, 6 R, 8 \mathrm{a} R)-6-[2-$ (1(2)H-tetrazole-5-yl) ethyl] decahydroisoquinoline-3-carboxylic acid. Neuropharmacology 34:1159-1168.

Shimizu E, Tang YP, Rampon C, Tsien JZ (2000) NMDA receptordependent synaptic reinforcement as a crucial process for memory consolidation. Science 290:1170-1174.

Smith-Roe SL, Kelley AE (2000) Coincident activation of NMDA and dopamine D1 receptors within the nucleus accumbens core is required for appetitive instrumental learning. J Neurosci 20:7737-7742.

Smith-Roe SL, Sadeghian K, Kelley AE (1999) Spatial learning and performance in the radial arm maze is impaired after $N$-methyl-Daspartate (NMDA) receptor blockade in striatal subregions. Behav Neurosci 113:703-717. 
Svensson L, Zhang J, Johannessen K, Engel JA (1994) Effect of local infusion of glutamate analogues into the nucleus accumbens of rats: an electrochemical and behavioural study. Brain Res 643:155-161.

Taepavarapruk P, Floresco SB, Phillips AG (2000) Hyperlocomotion and increased dopamine efflux in the rat nucleus accumbens evoked by electrical stimulation of the ventral subiculum: role of ionotropic glutamate and dopamine D1 receptors. Psychopharmacology 151:242-251.

Williams DR, Williams H (1969) Auto-maintenance in the pigeon: sustained pecking despite contingent non-reinforcement. J Exp Anal Behav 12:511-520.

Wolterink G, Phillips G, Cador M, Donselaar-Wolterink I, Robbins TW, Everitt BJ (1993) Relative roles of ventral striatal D1 and D2 dopa- mine receptors in responding with conditioned reinforcement. Psychopharmacology 110:355-364

Wu M, Brudzynski SM (1995) Mesolimbic dopamine terminals and locomotor activity induced from the subiculum. NeuroReport 6:1601-1604

Wu M, Brudzynski SM, Mogenson GJ (1993) Functional interaction of dopamine and glutamate in the nucleus accumbens in the regulation of locomotion. Can J Physiol Pharmacol 71:407-413.

Wyvell CL, Berridge KC (2000) Intra-accumbens amphetamine increases the conditioned incentive salience of sucrose reward: enhancement of reward "wanting" without enhanced "liking" or response reinforcement. J Neurosci 20:8122-8130. 